\title{
Factors and predictive model associated with perioperative complications after long fusion in the treatment of adult non- degenerative scoliosis
}

Nan $W^{1,2,3^{*}+}$, Jiashen Shao ${ }^{1,4+}$, Zhen Zhang ${ }^{1,4+}$, Shengru Wang ${ }^{1,2}$, Ziquan $\mathrm{Li}^{1}$, Sen Zhao ${ }^{1,2,3}$, Yang Yang ${ }^{1,2}$,

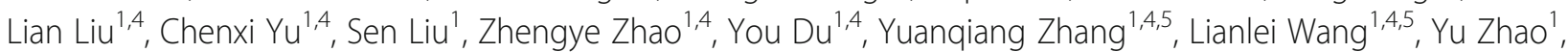
Keyi $\mathrm{Yu}^{1}$, Hong Zhao ${ }^{1}$, Jianxiong Shen ${ }^{1}$, Guixing Qiu ${ }^{1,2,3}$, Deciphering Disorders Involving Scoliosis and COmorbidities (DISCO) study, Zhihong Wu $\mathrm{W}^{1,3,6}$ and Terry Jianguo Zhang ${ }^{1,2,3^{*}}$

\begin{abstract}
Introduction: Adult non-degenerative scoliosis accounts for $90 \%$ of spinal deformities in young adults. However, perioperative complications and related risk factors of long posterior instrumentation and fusion for the treatment of adult non-degenerative scoliosis have not been adequately studied.

Methods: We evaluated clinical and radiographical results from 146 patients with adult non-degenerative scoliosis who underwent long posterior instrumentation and fusion. Preoperative clinical data, intraoperative variables, and perioperative radiographic parameters were collected to analyze the risk factors for perioperative complications. Potential and independent risk factors for perioperative complications were evaluated by univariate analysis and logistic regression analysis.
\end{abstract}

Results: One hundred forty-six adult non-degenerative scoliosis patients were included in our study. There were 23 perioperative complications for 21 (14.4\%) patients, eight of which were cardiopulmonary complications, two of which were infection, six of which were neurological complications, three of which were gastrointestinal complications, and four of which were incision-related complication. The independent risk factors for development of total perioperative complications included change in Cobb angle (odds ratio [OR] $=1.085,95 \% \mathrm{Cl}=1.035 \sim 1.137$, $P=0.001)$ and spinal osteotomy $(\mathrm{OR}=3.565,95 \% \mathrm{Cl}=1.039 \sim 12.236, P=0.043)$. The independent risk factor for minor perioperative complications is change in Cobb angle $(\mathrm{OR}=1.092,95 \% \mathrm{Cl}=1.023 \sim 1.165, P=0.008)$. The independent risk factors for major perioperative complications are spinal osteotomy $(\mathrm{OR}=4.475,95 \% \mathrm{Cl}=1.960 \sim$ $20.861, P=0.036)$ and change in Cobb angle $(\mathrm{OR}=1.106,95 \% \mathrm{Cl}=1.035 \sim 1.182, P=0.003)$.

\footnotetext{
* Correspondence: dr.wunan@pumch.cn; zhangjianguo@pumch.cn

${ }^{\dagger} \mathrm{Nan}$ Wu, Jiashen Shao and Zhen Zhang contributed equally to this work. 'Department of Orthopedic Surgery, Peking Union Medical College Hospital, Peking Union Medical College and Chinese Academy of Medical Sciences, Beijing 100730, China

Full list of author information is available at the end of the article
}

(c) The Author(s). 2021 Open Access This article is licensed under a Creative Commons Attribution 4.0 International License, which permits use, sharing, adaptation, distribution and reproduction in any medium or format, as long as you give appropriate credit to the original author(s) and the source, provide a link to the Creative Commons licence, and indicate if changes were made. The images or other third party material in this article are included in the article's Creative Commons licence, unless indicated otherwise in a credit line to the material. If material is not included in the article's Creative Commons licence and your intended use is not permitted by statutory regulation or exceeds the permitted use, you will need to obtain permission directly from the copyright holder. To view a copy of this licence, visit http://creativecommons.org/licenses/by/4.0/ The Creative Commons Public Domain Dedication waiver (http://creativecommons.org/publicdomain/zero/1.0/) applies to the data made available in this article, unless otherwise stated in a credit line to the data. 
Conclusions: Our study indicate that change in Cobb angle and spinal osteotomy are independent risk factors for total perioperative complications after long-segment posterior instrumentation and fusion in adult non-degenerative scoliosis patients. Change in Cobb angle is an independent risk factor for minor perioperative complications. Change in Cobb angle and spinal osteotomy are independent risk factors for major perioperative complications.

Keywords: Adult non-degenerative scoliosis, Perioperative complications, Risk factors, Long-segment posterior instrumentation and fusion

\section{Introduction}

Adult spinal deformities (ASD) can be classified into two subtypes: progression of childhood scoliosis (non-degenerative scoliosis) and degenerative scoliosis [1]. Because conservative treatment is often insufficient to effectively improve the diverse symptoms, surgical treatment is usually recommended. When a spinal surgery is advocated, determining the extent of the fusion is important. Long-segment instrumentation and fusion have been proven to be able to correct severe deformities and rotatory subluxations [2]. However, long fusions are also associated with excessive intraoperative blood loss, which contributes to the development of perioperative complications [3].

As life expectancy increases, adult degenerative scoliosis (ADS), or de novo scoliosis, is gaining more attention in the field. Patients with ADS suffer from pain, disability, and neurological symptoms [4]. The estimated incidence of postoperative complications has been reported to range from $16.4 \%$ to as high as $80 \%$ [5, 6]. Many risk factors for these complications have been reported, including massive intraoperative blood loss $(>2$ to $4 \mathrm{~L}$ ), age, the extent and approach of the surgery, and the presence of more than three comorbidities [7-9].

In contrast to ADS, adult non-degenerative scoliosis remains poorly studied. Non-degenerative factors are presumed to account for as high as $90 \%$ of the spinal deformities in young adults [10]. Although surgical correction of ASD is cost-effective and improves the qualityof-life and clinical outcomes for scoliosis patients when compared to the non-operative conservative treatment, it is not risk-free. In addition to being associated with worse clinical outcomes and further difficulties in treatment, perioperative complications can impose a substantial clinical and financial burden on state healthcare [11]. In this study, we aim to retrospectively evaluate the potential risk factors for perioperative complications stemming from the use of long-segment posterior-only instrumentation and fusion in the treatment of adult non-degenerative scoliosis.

\section{Materials and methods}

\section{Patients}

A single center-based, retrospective cohort study was performed on adult patients who had undergone long spinal fusions at the Department of Orthopedic Surgery, Peking Union Medical College Hospital. A total of 146 consecutive patients, who were diagnosed with adult non-degenerative scoliosis and who had undergone long-segment internal fixation and fusion by the conventional midline open posterior approach from January 2012 to July 2018, were selected and reviewed. The experimental protocol was reviewed and approved by the Ethics Committee of Peking Union Medical College Hospital (agreement number: JS-908). Our study was performed in accordance with experimental protocol and the Declaration of Helsinki, and informed consent was obtained from all participants.

Inclusion criteria for this study were operatively treated adult spinal deformity patients with the following conditions: (1) age $>18$ years by the time of the surgery, (2) major Cobb angle $\geq 40^{\circ}$, (3) posterior long-segment internal fixation and fusion ( $\geq 4$ vertebrae), (4) follow-up $\geq 1$ year, (5) complete preoperative and postoperative radiographic data and clinical evaluations, (6) complete medical history, and (7) the patient was diagnosed with idiopathic scoliosis. Exclusion criteria were (1) degenerative or de novo scoliosis (degenerative change without preexisting scoliosis typically manifested in the lumbar spine) and other kinds of secondary spinal deformities (e.g., ankylosing spondylitis, spinal tumor, iatrogenic spinal deformity, and posttraumatic spinal deformity); (2) previous history of lumbar surgery; and (3) anterior instrumentation or non-fusion surgery.

\section{Medical history and operative data}

Baseline characteristics, including age, sex, body mass index (BMI), presenting symptoms, any history of smoking, medication use, previous surgeries, comorbidities, preoperative hemoglobin ( $\mathrm{Hgb})$ level, and the length of hospital stay (LOS) were collected. American Society of Anesthesiologists (ASA) grades were evaluated by anesthetists. Fusion levels, distal instrumented and fusion levels, estimated blood loss (EBL), duration of the operation, and the volume of blood transfusions were charted. Perioperative complications were defined as any event for which the patient required a specific intervention or treatment. All complications that occurred before discharge were recorded and analyzed [12]. 
Perioperative complications were categorized as minor and major complications as previously defined [13]. Major complications were defined as the complications that were life-threatening or may adversely affect the outcome of the treatment. Minor complications were defined as medical events noted in the medical records but did not compromise outcome.

\section{Radiographic measurements}

For all patients, both anterior-posterior and lateral whole-spine X-rays were included to measure parameters. The following parameters, including sagittal vertical axis (SVA), thoracic kyphosis (TK), pelvic tilt (PT), sacral slope (SS), lumbar lordosis (LL), pelvic incidence (PI), and pelvic incidence minus lumbar lordosis (PI-LL), were recorded to assess the degree of spinal deformities in the coronal and sagittal plane. These data were measured on both the preoperative and the immediate postoperative radiographs. All measurements were performed independently by two spinal surgeons to decrease subjective bias.

\section{Statistical analysis}

Data analysis was performed with SPSS version 25.0 (SPSS, Inc., Chicago, IL, USA). Continuous variables are reported as mean \pm standard deviations (SD). Categorical variables are presented as a number or ratio. In the univariate testing, continuous variables were examined by the Student t-test. Categorical variables were tested by the Pearson chi-square test or Fisher's exact test, depending on which was appropriate. Predictors with a $P$ value $<0.2$ on univariate analysis were included in the multivariate analysis.

The selection of variables in the final model was not only driven by statistical power but also by clinical judgement, collinearity, and previously reported risk factors. These variables were analyzed using a binary logistic regression model. Variables that differed significantly between those groups were then entered into a multivariate logistic regression analysis to identify independent risk factors. We generated a receiver operating characteristic (ROC) curve using predicted probability values from the logistic regression. Data were analyzed using SPSS software 20.0 (Chicago, Illinois, USA).

\section{Result}

\section{Baseline characteristics and surgical characteristics}

A total of 146 patients were included in our study. The preoperative assessment showed that $33.5 \%$ of the patients in our cohort had mild or severe systemic disease (ASA 2-3). The lowest instrumented vertebra of most cases was at L4 or upper (121 patients, 82.8\%). Instrumented vertebral levels, ranging from 4 to 16 , could be divided into two groups: 4 to 10 (43 patients, 29.4\%) and
11 to 16 (103 patients, 66.5\%). Fusion levels, ranging from 4 to 15 , could be divided into two groups: 4 to 10 (60 patients, $41.1 \%$ ) and 11 to 15 (86 patients, $58.9 \%$ ). Decompression and osteotomy were performed in $2.1 \%$ (3 of 146) and 19.2\% (28 of 146) of our patients, respectively. The radiographic parameters were based on anterior-posterior and lateral whole-spine X-rays. Prior to surgery, the average Cobb angle, SVA, TK, PT, SS, LL, PI, and PI -LL were as follows: $59.1 \pm 19.7^{\circ}, 23.2 \pm$ $17.0 \mathrm{~mm}, 29.7 \pm 15.7^{\circ}, 9.6 \pm 7.9^{\circ}, 30.9 \pm 12.7^{\circ}, 46.4 \pm 16.4^{\circ}$, $39.8 \pm 16.1^{\circ}, 12.9 \pm 14.3^{\circ}$; the respective postoperative data were the following: $23.8 \pm 17.2^{\circ}, 19.4 \pm 16.1 \mathrm{~mm}$, $30.7 \pm 11.3^{\circ}, 10.3 \pm 7.7^{\circ}, 28.3 \pm 12.5^{\circ}, 43.8 \pm 12.4^{\circ}, 37.8 \pm$ $16.9^{\circ}, 8.1 \pm 8.4^{\circ}$. A summary of baseline characteristics and surgical characteristics is shown in Tables 1 and 2 .

\section{Perioperative complications}

Of 146 patients, there were 21 (14.4\%) patients who suffered from complications during the perioperative periods, including eight (34.8\%) cardiopulmonary complications, two $(8.7 \%)$ infection complications, six $(26.1 \%)$ neurological complications, three (13.0\%) gastrointestinal complications, and four (17.4\%) incision-related complications. Eighteen patients $(12.3 \%)$ suffered one complication. Two complications were recorded in each of 2 patients (1.4\%) (Table 3).

Different strategies were employed to deal with perioperative complications (Table 4). Closed thoracic drainage proved beneficial for patients with pleural effusion and atelectasis. To treat congestive heart failure, the patient's fluid status was closely monitored, and drugs were given to promote diuresis. Urinary infection was treated with urine culture and anti-infection drug. Acute neurological problems could be rapidly corrected by dehydration and steroid treatment, while chronic neurological symptoms required patience and a nerve-nurturing treatment. Generally, all symptoms tended to improve in the follow-up period.

\section{Univariate analysis}

Patients were divided into two groups based on whether they had any perioperative complications: without perioperative complication group (125) and with perioperative complications group (21). The results of univariate analysis investigating the relationships between baseline/ surgical characteristics and perioperative complications are shown in Tables 1 and 2. Factors that were found to carry a statistically significant weight in risk prediction were ASA classification $(P=0.048), \operatorname{LOS}(P=0.017)$, EBL $(P=0.061)$, levels of fusion $(P=0.026)$, spinal osteotomy $(P=0.038)$, preoperative Cobb angle $(P=0.004)$, change in Cobb angle $(P=0.022)$ and postoperative LL $(P=0.050)$. Predictors with $P$ values $<0.2$ were also considered eligible to be factored into risk calculations. 
Table 1 Demographics and baseline characteristics of included patients

\begin{tabular}{|c|c|c|c|}
\hline Characteristics & Without perioperative complication $(n=125)$ & With perioperative complication $(n=21)$ & $P$ value \\
\hline Age $(y / o)$ & $28.8 \pm 9.6$ & $32.9 \pm 10.7$ & 0.081 \\
\hline Gender (male \%) & & & 0.850 \\
\hline Male & $21(14.4 \%)$ & $2(1.4 \%)$ & \\
\hline Female & 104(71.2\%) & 19(13.0\%) & \\
\hline $\mathrm{BMI}\left(\mathrm{kg} / \mathrm{m}^{2}\right)$ & $20.4 \pm 2.8$ & $20.7 \pm 3.6$ & 0.687 \\
\hline Symptom duration (month) & $12.4 \pm 9.3$ & $15.5 \pm 10.0$ & 0.069 \\
\hline Smoking & & & 1 \\
\hline No & $120(82.2 \%)$ & $20(13.7 \%)$ & \\
\hline Yes & $5(3.4 \%)$ & $1(0.7 \%)$ & \\
\hline Heart disease & & & 0.717 \\
\hline No & $121(82.9 \%)$ & $20(13.7 \%)$ & \\
\hline Yes & $4(2.7 \%)$ & $1(0.7 \%)$ & \\
\hline Respiratory disease & & & 1 \\
\hline No & $116(79.5 \%)$ & $20(13.7 \%)$ & \\
\hline Yes & $9(6.2 \%)$ & $1(0.7 \%)$ & \\
\hline Hypertension & & & 0.346 \\
\hline No & 123(84.2\%) & $20(13.7 \%)$ & \\
\hline Yes & $2(1.4 \%)$ & $1(0.7 \%)$ & \\
\hline Anemia & & & 1 \\
\hline No & 124 (84.9\%) & $21(14.4 \%)$ & \\
\hline Yes & $1(0.7 \%)$ & $0(0.0 \%)$ & \\
\hline \multicolumn{4}{|l|}{ History of surgery } \\
\hline No & $99(67.8 \%)$ & $12(8.2 \%)$ & 0.068 \\
\hline Yes & $26(17.8 \%)$ & $9(6.2 \%)$ & \\
\hline ASA classification & & & 0.048 \\
\hline 1 & $87(59.6 \%)$ & $10(6.8 \%)$ & \\
\hline $2-3$ & $38(26.0 \%)$ & $11(7.5 \%)$ & \\
\hline
\end{tabular}

y/o years old, BMI body mass index, ASA American Society of Anesthesiologists

\section{Multivariate analysis}

Factors whose $P$ value $<0.2$ in the univariate analysis were selected for multivariate analysis. The independent risk factors for development of total perioperative complications included change in Cobb angle $(\mathrm{OR}=$ 1.085, 95\% $\mathrm{CI}=1.035 \sim 1.137, P=0.001)$ and spinal osteotomy $(\mathrm{OR}=3.565,95 \% \mathrm{CI}=1.039 \sim 12.236, P=$ $0.043)$. The area under the ROC curve based on predicted probability of the logistic regression was 0.842 (95\% CI $=0.734 \sim 0.949) \quad$ (Fig. 1a). The independent risk factor for minor perioperative complications is change in Cobb angle $(\mathrm{OR}=1.092,95 \% \mathrm{CI}=1.023$ $1.165, P=0.008)$. The area under the ROC curve based on predicted probability of the logistic regression was 0.818 (95\% CI =0.678 0.959) (Fig. 1b). The independent risk factors for major perioperative complications are spinal osteotomy $(\mathrm{OR}=4.475,95 \% \mathrm{CI}=$ $1.960 \sim 20.861, P=0.036)$ and change in Cobb angle
$(\mathrm{OR}=1.106,95 \% \mathrm{CI}=1.035 \sim 1.182, \quad P=0.003)$. The area under the ROC curve based on predicted probability of the logistic regression was 0.856 (95\% CI = $0.742 \sim 0.989$ ) (Fig. 1c). A summary of multivariate analysis results is shown in Table 5 .

\section{Discussion}

Non-degenerative factors are presumed to account for as high as $90 \%$ of spinal deformities in young adults [10]. ASD patients often undergo long-segment thoracolumbar arthrodesis that extends to the lower lumbar spine or the sacral region, and this procedure is associated with more perioperative complications [6]. The treatment for adult non-degenerative scoliosis aims not only to prevent further progression but also seeks to improve the existing manifestations [14]. In this study, we collected a cohort of data on the perioperative complications after surgical treatment of adult non-degenerative 
Table 2 Operative characteristics of included patients

\begin{tabular}{|c|c|c|c|}
\hline Characteristics & Without perioperative complication $(n=125)$ & With perioperative complication $(n=21)$ & $P$ value \\
\hline LIV & & & 0.952 \\
\hline L4 or upper & $103(70.5 \%)$ & $18(12.3 \%)$ & \\
\hline L5 or lower & $22(15.1 \%)$ & $3(2.1 \%)$ & \\
\hline RBC transfusion & & & 0.233 \\
\hline$<4 u$ & $106(72.6 \%)$ & 15(10.3\%) & \\
\hline$>=4 u$ & 19(13.0\%) & $6(4.2 \%)$ & \\
\hline Operative time (min) & $249.7 \pm 73.4$ & $260.9 \pm 73.8$ & 0.516 \\
\hline Length of hospital stay (day) & $13.4 \pm 4.0$ & $16.9 \pm 6.0$ & 0.017 \\
\hline Estimated blood loss (mL) & $689.9 \pm 415.5$ & $884.5 \pm 554.6$ & 0.061 \\
\hline Preoperative Hgb (g/L) & $130.9 \pm 15.1$ & $133.1 \pm 7.3$ & 0.288 \\
\hline Preoperative albumin (g/L) & $43.1 \pm 3.9$ & $42.6 \pm 2.5$ & 0.512 \\
\hline Fusion levels & & & 0.026 \\
\hline $4-10$ & $56(38.4 \%)$ & $4(2.7 \%)$ & \\
\hline $11-15$ & 69(47.3\%) & $17(11.6 \%)$ & \\
\hline Instrumented vertebral levels & & & 0.258 \\
\hline $4-10$ & $39(26.7 \%)$ & $4(2.7 \%)$ & \\
\hline $11-16$ & $86(58.9 \%)$ & $17(7.6 \%)$ & \\
\hline Decompression & & & 0.375 \\
\hline No & $123(84.2 \%)$ & $20(13.7 \%)$ & \\
\hline Yes & $2(1.4 \%)$ & $1(0.7 \%)$ & \\
\hline Spinal osteotomy & & & 0.038 \\
\hline No & 105(71.9\%) & $13(8.9 \%)$ & \\
\hline Yes & $20(13.7 \%)$ & $8(5.5 \%)$ & \\
\hline \multicolumn{4}{|l|}{$\operatorname{Cobb}\left({ }^{\circ}\right)$} \\
\hline Preoperative & $59.1 \pm 19.7$ & $73.1 \pm 21.9$ & 0.004 \\
\hline Postoperative & $23.8 \pm 17.2$ & $28.3 \pm 19.4$ & 0.274 \\
\hline Change & $35.3 \pm 10.2$ & $44.8 \pm 17.0$ & 0.022 \\
\hline \multicolumn{4}{|l|}{ SVA (mm) } \\
\hline Preoperative & $23.2 \pm 17.0$ & $20.3 \pm 20.8$ & 0.486 \\
\hline Postoperative & $19.4 \pm 16.1$ & $17.7 \pm 20.9$ & 0.663 \\
\hline Change & $15.0 \pm 13.7$ & $19.6 \pm 19.5$ & 0.315 \\
\hline \multicolumn{4}{|l|}{ TK $\left(^{\circ}\right)$} \\
\hline Preoperative & $29.7 \pm 15.7$ & $36.3 \pm 18.3$ & 0.086 \\
\hline Postoperative & $30.7 \pm 11.3$ & $35.7 \pm 13.4$ & 0.076 \\
\hline Change & $10.4 \pm 9.7$ & $10.1 \pm 7.3$ & 0.899 \\
\hline \multicolumn{4}{|l|}{ PT $\left(^{\circ}\right)$} \\
\hline Preoperative & $9.6 \pm 7.9$ & $9.0 \pm 7.8$ & 0.734 \\
\hline Postoperative & $10.3 \pm 7.7$ & $8.8 \pm 8.3$ & 0.413 \\
\hline Change & $5.4 \pm 4.6$ & $5.5 \pm 5.1$ & 0.898 \\
\hline \multicolumn{4}{|l|}{ SS $\left(^{\circ}\right)$} \\
\hline Preoperative & $30.9 \pm 12.7$ & $31.3 \pm 14.9$ & 0.900 \\
\hline Postoperative & $28.3 \pm 12.5$ & $27.9 \pm 15.5$ & 0.894 \\
\hline Change & $7.9 \pm 10.8$ & $10.4 \pm 10.0$ & 0.314 \\
\hline
\end{tabular}

$\mathrm{LL}\left({ }^{\circ}\right)$ 
Table 2 Operative characteristics of included patients (Continued)

\begin{tabular}{llll}
\hline Characteristics & Without perioperative complication $(\mathbf{n}=\mathbf{1 2 5})$ & With perioperative complication $(\mathbf{n}=\mathbf{2 1})$ & $\boldsymbol{P}$ value \\
\hline Preoperative & $46.4 \pm 16.4$ & $49.0 \pm 14.9$ & 0.492 \\
Postoperative & $43.8 \pm 12.4$ & $49.8 \pm 16.1$ & 0.050 \\
Change & $10.0 \pm 8.0$ & $11.8 \pm 7.9$ & 0.354 \\
PI ( $\left.{ }^{\circ}\right)$ & & & \\
Preoperative & $39.8 \pm 16.1$ & $38.8 \pm 20.1$ & $34.8 \pm 21.0$ \\
Postoperative & $37.8 \pm 16.9$ & $9.6 \pm 13.9$ & 0.810 \\
Change & $9.1 \pm 12.9$ & & 0.456 \\
PI-LL $\left(^{\circ}\right)$ & & $16.7 \pm 15.3$ & 0.877 \\
Preoperative & $12.9 \pm 14.3$ & $11.1 \pm 11.2$ & 0.246 \\
Postoperative & $8.1 \pm 8.4$ & $3.7 \pm 12.0$ & 0.143 \\
Change & $4.7 \pm 13.0$ & 0.256 \\
\hline
\end{tabular}

LIV lowest instrumented vertebra, $R B C$ red blood cell, SVA sagittal vertical axis, TK thoracic kyphosis, PT pelvic tilt, SS sacral slope, LL lumbar lordosis, $P I$ pelvic incidence, $P I-L L$ pelvic incidence minus lumbar lordosis

scoliosis. The results of multivariate analysis reveal that the change in Cobb angle and spinal osteotomy are independent risk factors for the development of perioperative complications, the change in Cobb angle is an independent risk factor for the development of minor perioperative complications, the change in Cobb angle and spinal osteotomy are independent risk factor for the development of major perioperative complications.

Surgical treatment is recommended when conservative treatment proves unsatisfactory, and decompression surgery is essential for alleviating symptoms. Most surgeons recommend fusion and instrumentation techniques for decompression [15]. Thus, choosing the proper extent of the fusion is key to a successful surgery. Long fusion and instrumentation proved successful in correcting scoliotic curvature and coronal imbalance. For patients with a large Cobb angle and rotatory subluxation, long fusion should be carried out to minimize adjacent segment disease [6]. All the patients selected for our study had long fusions, and their levels of distal fusions were different. Stopping a fusion at L5 can lead to subsequent degeneration at L5-S1. If the fusion extends to the sacrum, the procedure would be more complex, and there is a higher likelihood of pseudarthrosis at the lumbosacral junction. However, studies have found that long fusions terminating at L5 or the sacrum was similar in overall complication rate and improvement in pain and disability [16, 17]. In our study, we found no association between the incidence of perioperative complications and the level at which the fusion stopped $(P=0.952)$. There is a new instrument method, the S2AI iliac screw, which is designed to fix drawbacks such as screw site prominence and wound complication, that can successfully avoid the complications associated with conventional iliac screws [18]. However, this presumed reduction in perioperative complications in the S2AI group was not detected by our study, which might be due to our limited sample size.

Focused on adult non-degenerative scoliosis patients who underwent long fusion surgeries, we collected and analyzed all the parameters deemed relevant according to our clinical expertise and previous research, which involved collecting the patients' medical history, radiographic data, and clinical evaluations. Owing to the fact that most of our patients were relatively young, there was relatively little data on history of lumbar operation,

Table 3 Distribution of perioperative complications

\begin{tabular}{|c|c|c|c|c|c|}
\hline Type & Major perioperative complication & Number & Minor perioperative complication & Number of patients & Total \\
\hline \multirow[t]{2}{*}{ Cardiopulmonary } & Congestive heart failure & $1(4.3 \%)$ & Atelectasis & $1(4.3 \%)$ & $8(34.8 \%)$ \\
\hline & Pleural effusion & $6(26.1 \%)$ & & & \\
\hline Infection & & & Urinary infection & $2(8.7 \%)$ & $2(8.7 \%)$ \\
\hline \multirow[t]{2}{*}{ Neurological } & Nerve root injury & $1(4.3 \%)$ & Radicular edema & $2(8.7 \%)$ & $6(26.1 \%)$ \\
\hline & & & Sensory deficit & $3(13.0 \%)$ & \\
\hline Gastrointestinal & Acute pancreatitis & $1(4.3 \%)$ & lleus & $2(8.7 \%)$ & $3(13.0 \%)$ \\
\hline \multirow[t]{2}{*}{ Incision-related } & Fat liquefaction & $2(8.7 \%)$ & Non-aligned edges & $1(4.3 \%)$ & $4(17.4 \%)$ \\
\hline & & & Atopic dermatitis & $1(4.3 \%)$ & \\
\hline
\end{tabular}


Table 4 Category, management and treatment outcomes of perioperative complications

\begin{tabular}{|c|c|c|c|}
\hline Category & Symptoms and signs & Management & Results \\
\hline \multirow[t]{2}{*}{ Cardiopulmonary } & Pleural effusion, atelectasis & Thoracic closed drainage & Recovered in $2 \mathrm{w}$ postoperatively \\
\hline & Congestive heart failure & $\begin{array}{l}\text { Consultation with cardiology, myocardium-nurturing, and } \\
\text { control fluid infusion }\end{array}$ & Recovered in $1 \mathrm{w}$ postoperatively \\
\hline Infection & Urinary infection & Urine culture, anti-infection drug & Recovered in $2 \mathrm{w}$ postoperatively \\
\hline \multirow[t]{3}{*}{ Neurological } & Radicular edema & Dehydration and steroid treatment & Recovered \\
\hline & $\begin{array}{l}\text { Sensory deficit, peripheral } \\
\text { nerve palsy }\end{array}$ & Dehydration and nerve-nurturing treatment & Recovered in $4 \mathrm{w}$ postoperatively \\
\hline & Nerve root injury & Revision surgery & Recovered \\
\hline \multirow[t]{2}{*}{ Gastrointestinal } & lleus & $\begin{array}{l}\text { Fasting and water deprivation, acid-suppressive drugs, liquid } \\
\text { paraffin, and glycerine enema }\end{array}$ & Recovered in $2 \mathrm{w}$ \\
\hline & Acute pancreatitis & $\begin{array}{l}\text { Fluid replacement, monitoring electrolytes and oxygen } \\
\text { saturation, anti-infection, and acid-suppressive drugs }\end{array}$ & Recovered in $2 \mathrm{w}$ postoperatively \\
\hline \multirow[t]{3}{*}{ Incision } & Fat liquefaction & Debridement and suture & Recovered in $1 \mathrm{w}$ postoperatively \\
\hline & Non-aligned edges & Dressing change and anti-infection drugs & Recovered in $1 \mathrm{w}$ postoperatively \\
\hline & Atopic dermatitis & Maintaining skin hydration and topical anti-inflammatory therapy & Recovered \\
\hline
\end{tabular}

previous medication use, or whether there were any ageassociated comorbidities such as diabetes and osteoporosis, some of which could be potential risk factors for ADS. Several studies have reported a direct correlation between parameters such as the ASA grade, Cobb angle, total operation time, PT, level of fusion, LOS, staging, multiple surgeries and the incidence of perioperative complications in ADS [9, 19-22]. However, further research is needed to identify the risk factors for perioperative complications in adult non-degenerative scoliosis.

In this study, change of main Cobb angle were significantly associated with the risk of minor and major perioperative complications. We included changes of all parameters in our analysis, which have rarely been reported in previous studies. Previous studies have shown that preoperative magnitude of the spinal curvature and coronal imbalance was associated with the likelihood of complications. Some author reported that an increased Cobb angle is associated with impaired pulmonary function due to airway blockage [23]. A higher risk of postoperative non-neurological complications, pulmonary compromise in particular, could be caused by a larger Cobb angle in adults and juvenile scoliosis patients [24]. An increased Cobb angle causes abnormal chest and lung development and results in less reserved space for ventilation.

Osteotomy is an effective procedure to correct spinal deformity, but it is often accompanied by some complications. In the Sciubba's study, they found that the most common complication after three-column osteotomies was neurological deficits [25]. In the Buchowski's study,


Fig. 1 The ROC curve using predicted probability values from the logistic regression. a ROC curve of risk factors predicting total perioperative complications, b ROC curve of risk factors predicting minor perioperative complications, c ROC curve of risk factors predicting major perioperative complications 
Table 5 Multivariate analysis of risk factors of perioperative complications

\begin{tabular}{lllll}
\hline Complication & Variables & OR & $\mathbf{9 5 \%}$ Cl & $\boldsymbol{P}$ value \\
\hline Total complication & Spinal osteotomy & 3.565 & $1.039,12.236$ & 0.043 \\
& Cobb angle change & 1.085 & $1.035,1.137$ & 0.001 \\
Minor complication & Cobb angle change & 1.092 & $1.023,1.165$ & 0.008 \\
Major complication & Spinal osteotomy & 4.475 & $1.960,20.861$ & 0.036 \\
& Cobb angle change & 1.106 & $1.035,1.182$ & 0.003 \\
\hline
\end{tabular}

OR odds ratio, $\mathrm{Cl}$ confidence interval, LL lumbar lordosis, ASA American Society of Anesthesiologists

they reported that the incidence of neurological complications was $11.1 \%$ after lumbar pedicle subtraction osteotomies (PSO) [26]. In our study, osteotomy procedure was significantly associated with the risk of total perioperative complications $(P=0.043$, OR $=3.565,95 \% \mathrm{CI}=$ $1.039,12.236)$ and major perioperative complications $(P=0.036, \mathrm{OR}=4.475,95 \% \mathrm{CI}=1.960,20.861)$. We consider that osteotomy procedure is usually associated with large surgical injury, which not only causes a high incidence of nerve injury, but also leads to abnormal homeostasis and stress states in patients. The combined effect of these factors may lead to the occurrence of complications.

There are some limitations to our study. First, the most significant being its retrospective nature. Second, in this study, all of the data was obtained from single medical center, and results were not validated by other centers. Third, due to the relatively young age of many of our patients, the effect of comorbidities that are more prevalent in elderly populations could not be adequately investigated.

In summary, we observed a 21 of 146 patients experienced complications during the perioperative periods. The change in Cobb angle and spinal osteotomy may contribute to the development of perioperative complications. The identification of these risk factors has potential to help stratify preoperative risks and reduce the incidence of complications.

\begin{abstract}
Abbreviations
OR: odds ratio; RBC: red blood cell; ROC: receiver operating characteristic; ASD: adult spinal deformities; ADS: adult degenerative scoliosis; BMl: body mass index; Hgb: hemoglobin; ASA: American Society of Anesthesiologists; SVA: sagittal vertical axis; TK: thoracic kyphosis; PT: pelvic tilt; SS: sacral slope; LL: lumbar lordosis; PI: pelvic incidence; PI-LL: pelvic incidence minus lumbar Iordosis; LOS: length of hospital stays; AIS: adolescent idiopathic scoliosis
\end{abstract}

\section{Acknowledgements}

We are grateful to the patients, their families and clinical surgeons for providing samples and clinical histories.

\section{Guideline statement}

All experiments were performed in accordance with relevant guidelines and regulations.

\section{Authors' contributions}

$\mathrm{Nan} \mathrm{Wu}$, Jiashen Shao and Zhen Zhang made substantial contributions to the conception and design of the work. Shengru Wang, Ziquan Li, Sen Zhao, Yuangiang Zhang and Lianlei Wang made contributions to the acquisition and analysis of data. Nan Wu, Jiashen Shao and Zhen Zhang drafted the manuscript. Yang Yang, Lian Liu, Chenxi Yu, Sen Liu, Zhengye Zhao and You Du helped with data management and statistical analysis. Yu Zhao, Keyi Yu, Hong Zhao, Jianxiong Shen, Guixing Qiu and Zhihong Wu helped to revised manuscript critically for important intellectual content. Terry Jianguo Zhang helped to revised manuscript and offered professional discussions and instructions. All authors approved the final version to be published.

\section{Funding}

This work was supported by the National Key Research and Development Program of China (No. 2017YFC1 104902 to J.Z. and No. 2018YFC0910500 to Z.W. and N.W.); the National Natural Science Foundation of China (No. 81672123,81972037 to J.Z.; No. 81822030 to N.W. and No. 81772299 to Z.W.); Beijing Natural Science Foundation (No. 7172175 to N.W. and No. L192015 to J.Z.); the Central Level Public Interest Program for Scientific Research Institute (No. 2018 RC31003 to N.W.), and the CAMS Initiative Fund for Medical Sciences (No. 2016-I2M-3-003 to N.W.).

\section{Availability of data and materials}

All of the patient's medical record and images are kept in Peking Union Medical College Hospital. For the review, please refer to the method section.

\section{Declarations}

\section{Ethics approval and consent to participate}

The study was approved by the Ethical Review Board of the Peking Union Medical College Hospital (agreement number: JS-908). Written informed consent was provided by each participant.

\section{Consent for publication}

Written informed consent for publication of clinical details and/or clinical images was obtained from the all of the participants.

\section{Competing interests}

The authors declare that they have no competing interests.

\section{Author details}

'Department of Orthopedic Surgery, Peking Union Medical College Hospital, Peking Union Medical College and Chinese Academy of Medical Sciences, Beijing 100730, China. ${ }^{2}$ Key Laboratory of Big Data for Spinal Deformities, Chinese Academy of Medical Sciences, Beijing 100730, China. ${ }^{3}$ Beijing Key Laboratory for Genetic Research of Skeletal Deformity, Beijing 100730, China. ${ }^{4}$ Graduate School of Peking Union Medical College, Beijing 100005, China. ${ }^{5}$ Department of Orthopedic Surgery, Qilu Hospital of Shandong University, Jinan 250012, China. ${ }^{6}$ Medical Research Center, Peking Union Medical College Hospital, Peking Union Medical College and Chinese Academy of Medical Sciences, Beijing, China.

Received: 3 December 2020 Accepted: 10 May 2021

Published online: 25 May 2021

\section{References}

1. Diebo B, Shah N, Boachie-Adjei O, Zhu F, Rothenfluh D, Paulino C, et al. Adult spinal deformity. Lancet. 2019;394(10193):160-72. https://doi.org/10.1 016/S0140-6736(19)31125-0.

2. Berjano $P$, Lamartina C. Classification of degenerative segment disease in adults with deformity of the lumbar or thoracolumbar spine. Eur Spine J. 2014;23(9):1815-24. https://doi.org/10.1007/s00586-014-3219-9.

3. Youssef J, Orndorff D, Patty C, Scott M, Price H, Hamlin L, et al. Current status of adult spinal deformity. Global Spine J. 2012;03(01):051-62.

4. Cho KJ, Kim YT, Shin SH, Suk SI. Surgical treatment of adult degenerative scoliosis. Asian Spine J. 2014;8(3):371-81. https://doi.org/10.4184/asj.2014. 8.3.371.

5. Bess S, Boachie-Adjei O, Burton D, Cunningham M, Shaffrey C, Shelokov A, et al. Pain and disability determine treatment modality for older patients with adult scoliosis, while deformity guides treatment for younger patients. 
Spine (Phila Pa 1976). 2009;34(20):2186-90. https://doi.org/10.1097/BRS 0b013e3181 b05146.

6. Cho KJ, Suk SI, Park SR, Kim JH, Kim SS, Lee TJ, et al. Short fusion versus long fusion for degenerative lumbar scoliosis. Eur Spine J. 2008;17(5):650-6. https://doi.org/10.1007/s00586-008-0615-z.

7. Auerbach JD, Lenke LG, Bridwell KH, Sehn JK, Milby AH, Bumpass D, et al. Major complications and comparison between 3-column osteotomy techniques in 105 consecutive spinal deformity procedures. Spine (Phila Pa 1976). 2012;37(14):1198.

8. Bianco KNR, Schwab F, Smith JS, Klineberg E, Obeid I, Mundis G Jr, et al. Complications and intercenter variability of three-column osteotomies for spinal deformity surgery: a retrospective review of 423 patients. Neurosurg Focus. 2014;36(5):E18.

9. Schwab FJ, Hawkinson N, Lafage V. Risk factors for major peri-operative complications in adult spinal deformity surgery: a multi-center review of 953 consecutive patients. Eur Spine J. 2012;21 (12):2603-10. https://doi.org/1 0.1007/s00586-012-2370-4.

10. Carter OD, Haynes SG. Prevalence rates for scoliosis in US adults: results from the first National Health and nutrition examination survey. Int J Epidemiol. 1987;16(4):537-44. https://doi.org/10.1093/ije/16.4.537.

11. Yeramaneni S, Robinson C, Hostin R. Impact of spine surgery complications on costs associated with management of adult spinal deformity. Curr Rev Musculoskelet Med. 2016;9(3):327-32. https://doi.org/10.1007/s12178-016-9352-9.

12. Carreon L, Puno R, Dimar J, Glassman S, Johnson J. Perioperative complications of posterior lumbar decompression and arthrodesis in older adults. J Bone Joint Surg Am. 2003;85(11):2089-92. https://doi.org/10.2106/ 00004623-200311000-00004.

13. Carreon LY, Puno RM, Dimar JR 2nd, Glassman SD, Johnson JR. Perioperative complications of posterior lumbar decompression and arthrodesis in older adults. J Bone Joint Surg Am. 2003;85(11):2089-92. https://doi.org/10.2106/ 00004623-200311000-00004.

14. Trobisch P, Suess O, Schwab F. Idiopathic scoliosis. Dtsch Arztebl Int. 2010; 107(49):875-83.

15. Daffner SD, Vaccaro AR. Adult degenerative lumbar scoliosis. Am J Orthop (Belle Mead NJ). 2003;32(2):77-82.

16. Daniels AH, Koller H, Hiratzka SL, Mayer M, Meier O, Contag AG, et al. Selecting caudal fusion levels: 2year functional and stiffness outcomes with matched pairs analysis in multilevel fusion to $L 5$ versus $S 1$. Eur Spine $J$. 2017;26(6):1645-51. https://doi.org/10.1007/s00586-016-4790-z.

17. Jia F, Wang G, Liu X, Li T, Sun J. Comparison of long fusion terminating at $L 5$ versus the sacrum in treating adult spinal deformity: a meta-analysis. Eur Spine J. 2020;29(1):24-35. https://doi.org/10.1007/s00586-019-06187-8.

18. Hasan MY, Liu G, Wong HK, Tan JH. Postoperative complications of S2AI versus iliac screw in spinopelvic fixation: a meta-analysis and recent trends review. Spine J. 2020;20(6):964-72. https://doi.org/10.1016/j.spinee.2019.11. 014.

19. Charosky S, Guigui P, Blamoutier A, Roussouly P, Chopin D. Complications and risk factors of primary adult scoliosis surgery: a multicenter study of 306 patients. Spine (Phila Pa 1976). 2012;37(8):693-700. https://doi.org/10.1097/ BRS.0b013e31822ff5c1.

20. Master DL, Son-Hing JP, Poe-Kochert C, Armstrong DG, Thompson GH. Risk factors for major complications after surgery for neuromuscular scoliosis. Spine (Phila Pa 1976). 2011;36(7):564-71. https://doi.org/10.1097/BRS.0b013 e3181e193e9.

21. Wang H, Zhang Z, Qiu G, Zhang J, Shen J. Risk factors of perioperative complications for posterior spinal fusion in degenerative scoliosis patients: a retrospective study. BMC Musculoskelet Disord. 2018;19(1):242. https://doi. org/10.1186/s12891-018-2148-X.

22. Zhang $X$, Sun $X$, Meng $X$, Hai Y. Risk factors for medical complications after long-level internal fixation in the treatment of adult degenerative scoliosis. Int Orthop. 2018;42(11):2603-12. https://doi.org/10.1007/s00264-018-3927-6.

23. Xue $X$, Shen J, Zhang J, Zhao H, Li S, Wang Y, et al. An analysis of thoracic cage deformities and pulmonary function tests in congenital scoliosis. Eur Spine J. 2015;24(7):1415-21. https://doi.org/10.1007/s00586-014-3327-6.

24. Wang $Y$, Hai $Y$, Liu Y, Guan L, Liu T. Risk factors for postoperative pulmonary complications in the treatment of non-degenerative scoliosis by posterior instrumentation and fusion. Eur Spine J. 2019;28(6):1356-62. https://doi. org/10.1007/s00586-019-05968-5.

25. Sciubba DM, Yurter A, Smith JS, Kelly MP, Scheer JK, Goodwin CR, et al. A comprehensive review of complication rates after surgery for adult deformity: a reference for informed consent. Spine Deform. 2015;3(6):57594. https://doi.org/10.1016/j.jspd.2015.04.005.

26. Buchowski JM, Bridwell KH, Lenke LG, Kuhns CA, Lehman RA Jr, Kim YJ, et al. Neurologic complications of lumbar pedicle subtraction osteotomy: a 10-year assessment. Spine (Phila Pa 1976). 2007;32(20):2245-52. https://doi. org/10.1097/BRS.0b013e31814b2d52.

\section{Publisher's Note}

Springer Nature remains neutral with regard to jurisdictional claims in published maps and institutional affiliations.
Ready to submit your research? Choose BMC and benefit from:

- fast, convenient online submission

- thorough peer review by experienced researchers in your field

- rapid publication on acceptance

- support for research data, including large and complex data types

- gold Open Access which fosters wider collaboration and increased citations

- maximum visibility for your research: over $100 \mathrm{M}$ website views per year

At BMC, research is always in progress.

Learn more biomedcentral.com/submissions 